\title{
Spatial Control of Flocculation via Light
}

\author{
Zeyun Xiao, ${ }^{1}$ Chao Chen, ${ }^{1}$ Emma Ruth Lucille Brisson, ${ }^{1}$ Joseph Collins, ${ }^{1}$ Wei Sung $\mathrm{Ng},{ }^{1}$ Luke A. Connal ${ }^{1}$ \\ ${ }^{1}$ Department of Chemical and Biomolecular Engineering, the University of Melbourne, Parkville, Victoria \\ 3010, Australia
}

Correspondence to: Luke A. Connal (E-mail: luke.connal@unimelb.edu.au)

(Additional Supporting Information may be found in the online version of this article.)

KEYWORDS: cross-linking; flocculation; light-responsive; polyethyleneimine; thiobenzaldehyde

Over the past decade, considerable efforts have been made in the area of stimuli-responsive chemistry which have led to the development of new tailored smart materials. ${ }^{1}$ The use of light to modulate stimuli-responsive systems is a powerful strategy to remotely and accurately control material properties. ${ }^{2-4}$ Thus, efficient photochemical reactions are not only the pursuit of organic and polymer chemistry which demand reactions take place under neutral and reagent-free conditions, but are also highly applicable in materials chemistry and biology to mediate processes in a spatially and temporally controlled manner. ${ }^{5-7}$ In this study, we present a highly efficient photo-initiated flocculation system formed through the trapping of a photogenerated thiobenzaldehyde with polyethylenimines (PEIs). The photo controlled flocculation has been further demonstrated in the removal of $\mathrm{Cu}^{2+}$.

Flocculation is an important separation method utilized in many industrial processes such as papermaking, water treatment and mineral processing. ${ }^{8}$ In a typical flocculation process, particles or colloids come out of suspension in the form of flocs or flakes; either spontaneously or due to the addition of a clarifying agent. ${ }^{9}$ PEls are frequently used flocculants in a variety of flocculation processes. In mineral processing, PEls are used in the flocculation of minerals such as kaolin slurries. ${ }^{10}$ They are also used as chelating agents for metal ions such as zinc and zirconium. $^{11}$ In microbiology, PEls find applications in the flocculation of dispersed E.coli bacterial cells. ${ }^{12}$ In addition, PEls are able to selectively flocculate nucleic acids, lipid, and colloidal particulate material from cell homogenates. ${ }^{13}$ In wastewater treatment, modified PEls are employed as heavy metal flocculants for removing toxic heavy metals such as $\mathrm{Hg}^{2+} \cdot{ }^{14}$ Furthermore, PEls are useful in bacterial sludge dewatering. ${ }^{15}$ The flocculating abilities of PEls are derived from the amine groups which also provide a platform for functionalization. One simple click-type reaction available is the reaction between the PEI amine with an aldehyde or thioaldehyde to form the corresponding imine. Compared with aldehydes, thioaldehydes are more reactive and can be generated efficiently under UV irradiation, thereby enabling spatial and temporal control over the imine formation (Scheme 1). ${ }^{16}$

SCHEME 1 Structures of thiobenzaldehyde precursors and the photo generated thiobenzaldehydes.

Thioaldehydes are among the most reactive species in organic chemistry and have been reported to be trapped by nitrile oxides, dienes, amines, hydroxylamines and thiols. ${ }^{6-7}$ Because of their high reactivity it is crucial to engineer molecules with masked thioaldehydes, that can be unmasked upon a trigger. The trapping of

This is the author manuscript accepted for publication and has undergone full peer review but has not been through the copyediting, typesetting, pagination and proofreading process, which may lead to differences between this version and the Version record. Please cite this article as doi:10.1002/ pola.28242. 
the photo-generated thioaldehydes has been applied to a series of surface modification applications by Barner-Kowollik and coworkers. ${ }^{6-7}$ We envisioned that the photogenerated thioaldehydes could be trapped by branched PEls via the imine formation reaction. The photo-initiated click-type reaction could be used for cross-linking the PEI to initiate the flocculation of metals. In Barner-Kowollik's work, the thioaldehyde precursors were synthesized by the condensation reaction of alcohols and phenacylthio acetic acid. ${ }^{6-7}$ After column chromatography separation, the thioaldehyde precursors were obtained in low to moderate yields. Here we used a simple onepot reaction to synthesize thiobenzaldehyde precursors (Scheme 2). ${ }^{17}$ In this method, benzyl bromide or $p$-xylene dibromide first reacted with thiourea to form $S$-alkylisothiouronium salts. The $S$-alkylisothiouronium salt intermediates were then treated with bromoacetophenone under a basic phase transfer condition to afford the thiobenzaldehyde precursor $\mathbf{1}$ and $\mathbf{2}$ in very high yields ( $93 \%$ and $88 \%$, respectively). Importantly, purification of the products was achieved by crystallization from ethyl acetate and the column-free procedure makes the precursors viable for large scale synthesis.

SCHEME 2 One pot synthesis of the thiobenzaldehyde precursors $\mathbf{1}$ and $\mathbf{2}$ in high yield and purification via crystallization.

Thiobenzaldehyde precursors $\mathbf{1}$ and $\mathbf{2}$ exhibit similar absorption spectra with a maximum absorption at $327 \mathrm{~nm}$ (Supporting Information, Figure S1). The absorption spectra are in good match with the emission spectrum of common hand-held fluorescent lamps $(\lambda=355 \mathrm{~nm})$, which contributes to the high efficiencies of the photo reactions. ${ }^{18}$ To confirm the light triggered thiobenzaldehyde formation and the trapping of the thiobenzaldehyde with amine, a model reaction in $\mathrm{CDCl}_{3}$ with ethylenediamine as the trapping agent was performed under UV light (320-400 nm UV intensity $\left.2.3 \mathrm{~mW} / \mathrm{cm}^{2}\right)$. The photo reactions were completed within 10 minutes and the imine products $\mathbf{3}$ and $\mathbf{4}$ were identified by ${ }^{1} \mathrm{H}$ NMR (Figure S2). Proton signals corresponding to $\mathrm{H}_{\mathrm{g}}, \mathrm{H}_{\mathrm{h}}$ in $\mathbf{1}$ and $\mathrm{H}_{\mathrm{g}^{\prime}}, \mathrm{H}_{\mathrm{h}^{\prime}}$ in $\mathbf{2}$ disappeared completely indicating the cleavage of the $\mathrm{C}-\mathrm{S}$ bond. Meanwhile, imine proton signals of $\mathrm{H}_{4}$ and $\mathrm{H}_{4}$, were observed (Figure 1). The cleavage of $\mathbf{1}$ and $\mathbf{2}$ released acetophenone which was also visible in the NMR spectra.
FIGURE 1 Trapping of the photo-generated thiobenzaldehydes with ethylenediamine. (a) Partial ${ }^{1} \mathrm{H}$ NMR changes before (lower) and after (upper) $10 \mathrm{~min}$ UV irradiation of $\mathbf{1}$ and ethylenediamine in $\mathrm{CDCl}_{3}$. (b) Partial ${ }^{1} \mathrm{H}$ NMR changes before (lower) and after (upper) $10 \mathrm{~min}$ UV irradiation of $\mathbf{2}$ and ethylenediamine in $\mathrm{CDCl}_{3}$. To avoid insoluble polymer formation, 
diamine to thioaldehyde molar ratios of $15: 1$ were used in the experiments.

To directly compare the reactivity of thiobenzaldehydes to benzaldehydes, reactions were performed under identical conditions (under UV light) with benzaldehyde and terephthalaldehyde as reactants (Figure S2). After 10 minutes, the benzaldehyde proton ( $\delta$ 9.89) was still visible on the NMR spectrum ( $81 \%$ and $78 \%$ conversion of the aldehyde group). On the other hand, the photo initiated reactions of $\mathbf{1}$ (or $\mathbf{2}$ ) and ethylenediamine were completed in 10 minutes giving quantitative yields. A kinetic study of the model reaction was also performed by irradiating ethylenediamine and 1 (molar ratio $8: 1$ ) for $2 \mathrm{~min}, 4 \mathrm{~min}, 6 \mathrm{~min}$, $8 \mathrm{~min}$ and $10 \mathrm{~min}$. The conversion rates of the reaction to compound $\mathbf{3}$ (based on NMR integration) were $49 \%, 70 \%, 83 \%, 91 \%$ and 96 , respectively (Figure S3). These results demonstrate the high efficiency of the photo cleavage reaction and also the high reactivity of the thiobenzaldehyde trapping with an amine, showing similar reactivity as the oxime click recation. ${ }^{19,} 20$ It is worth noting that water does not hinder this reaction as the imine product was also obtained with $\mathrm{CD}_{3} \mathrm{CN} / \mathrm{D}_{2} \mathrm{O}$ (v/v 3:1) as the solvent (Figure S4). Even though ketone groups are presented in $\mathbf{1}$ and $\mathbf{2}$, the condensation reaction of the ketone with the amine was not observed in the studied conditions and time scale. This phenomenon could be attributed the steric hindrance of the adjacent phenyl groups.

With the model reaction performed efficiently, the thiobenzaldehydes generated from precursors $\mathbf{1}$ and $\mathbf{2}$ were then treated with PEIs. The reaction between thiobenzaldehyde from 1 and PEI was followed by ${ }^{1} \mathrm{H}$ NMR. The proton signals of $\mathrm{H}_{\mathrm{g}}$ and $\mathrm{H}_{h}$ again disappeared after irradiation indicating the cleavage of the $\mathrm{C}$-S bond (Figure 2a). A new broad peak at $\delta=8.32$ was observed, which is attributed to the benzylimine proton $\mathrm{H}_{4}$ as the chemical shift is quite similar to that of the small molecular benzylimine proton (Figure 1a). ${ }^{21}$ There are primary, secondary and tertiary amine groups in PEI. It is well known the tertiary amine does not form imine. In the case of the secondary amine, since there is no $\alpha$-proton in the thiobenzaldehydes, it is not possible to form stabilized enamines. Therefore, the reaction product is attributed to the benzylimine functionalized PEI.

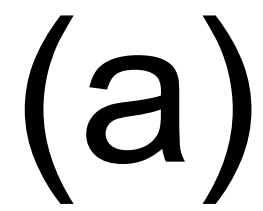

FIGURE 2 Photo-initiated functionalization of PEls with thiobenzaldehydes from $\mathbf{1}$ (a) and $\mathbf{2}$ (b) and partial ${ }^{1} \mathrm{H}$ NMR changes before and after the UV irradiation. Bottom ${ }^{1} \mathrm{H} N M R$ spectra are before UV irradiation, upper ${ }^{1} \mathrm{H}$ NMR spectra are after UV irradiation. The benzylimine functionalized PEI is soluble in $d_{6}$-DMSO while the cross-linked PEI is not soluble.

After UV irradiation, the thiobenzaldehydes generated from 2 reacted with PEI and formed an insoluble white floc. This phenomenon was observed even when a small molecular weight PEI $(M n=0.6 \mathrm{kDa})$ was used. Thus, in the NMR spectrum, only proton signals of acetophenone were shown (Figure $2 b$ ). The formation of the imine was then confirmed by FTIR. The 
functionalized PEls show a peak in the 1640$1645 \mathrm{~cm}^{-1}$ spectral range, characteristic for imine vibration, indicating the presence of the newly formed imine linkage (Figure 3 and Figure S5). On the other hand, the peak around 1590 $\mathrm{cm}^{-1}$, characteristic for free amino group of PEI decreases in intensity. ${ }^{22}$ The mono-substituted phenyl group displays a strong aromatic $\mathrm{C}-\mathrm{H}$ vibration band at $752 \mathrm{~cm}^{-1}$ while the $p$ disubstituted phenyl group shows a strong aromatic $\mathrm{C}-\mathrm{H}$ vibration band at $820 \mathrm{~cm}^{-1}$ which are characteristic to mono- and di-substituted phenyl groups. It should be noted that the reaction of $\mathrm{PEI}$ with thiobenzaldehyde generated from 1 does not form any floc. The formation of the cross-linked and insoluble products from PEI and compound 2 after UV irradiation (Figure 4a) makes this system applicable for spatial and temporal control of flocculation.

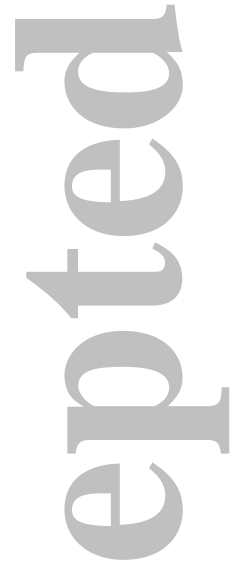

FIGURE 3 FTIR spectra of PEI and the imine functionalized PEls. Black, PEI before functionalization; red, benzylimine functionalized PEI; blue, cross-linked PEI.

Copper is extensively used in semiconductor circuits as the multi-layer metal. The classical chemical mechanical planarization (CMP) process in semiconductor industry generates a large amount of $\mathrm{Cu}$ containing waste. ${ }^{23} \mathrm{PEI}$ is frequently used as the chelator for $\mathrm{Cu}$ absorption and removal. ${ }^{24}$ To demonstrate the spatial control of flocculation, the photo initiated flocculation system was used in the process of $\mathrm{Cu}$ chelation and removal. In a proof- of-concept experiment, PEI was added to a $\mathrm{Cu}^{2+}$ $\left(2.5 \times 10^{-3} \mathrm{M}\right)$ solution to afford a blue PEI- $\mathrm{Cu}^{2+}$ complex solution (Figure $4 \mathrm{~b}$ and $\mathrm{S} 6$ ). ${ }^{25}$ At the studied concentration, the solution is quite stable even after standing for weeks. With the thiobenzaldehyde precursor 2, PEI forms flocs under UV irradiation. The $\mathrm{Cu}^{2+}$ ion was removed from water with the floc simultaneously as evidenced by the gradual disappearance of the blue color (Figure 4b). (a)
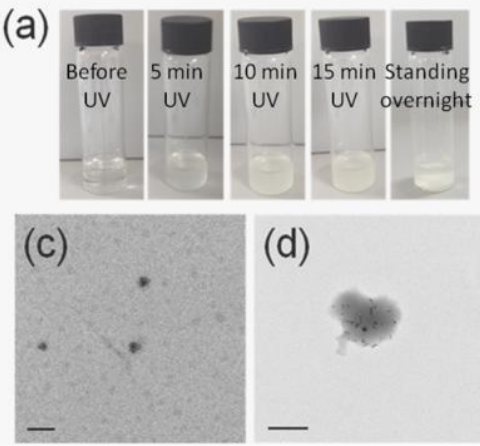

(b)

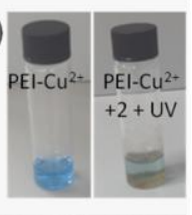

(d)

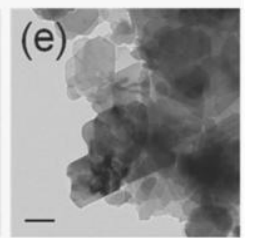

FIGURE 4 (a) From right to left: PEI and 2 dissolved in DMSO/ $\mathrm{H}_{2} \mathrm{O}(\mathrm{v} / \mathrm{v}$ 3:1) before and after irradiation for $5,10,15 \mathrm{~min}$ and left to standing overnight. (b) Right, $\mathrm{PEI}-\mathrm{Cu}^{2+}$ complex in water; left, 2 was added and irradiated under UV. (c), (d) and (e), TEM image of the microstructure of $\mathrm{PEI}$ and the flocculates formed by UV irradiation. (c) PEI deposited from aqueous solution. (d) Flocculate of PEI and $\mathbf{2}$ after UV irradiation. (e) Flocculate of $\mathrm{PEI}-\mathrm{Cu}^{2+}$ complex and $\mathbf{2}$ after UV irradiation. Scale bar: (c) $100 \mathrm{~nm}$, (d) $500 \mathrm{~nm}$, (e) $200 \mathrm{~nm}$.

To further investigate the flocculation process, the micro structures of the floc with and without $\mathrm{Cu}^{2+}$ were studied with TEM (Figure 4c4e). The low molecular weight PEI used in the study is a viscous oil and formed a thin layer after deposition from aqueous solution (Figure 4a). Cross-linked gel particles (or flocs) were observed when PEI and $\mathbf{2}$ were reacted under photochemical conditions, with aggregated structures sizes up to $500 \mathrm{~nm}$ (Figure $4 \mathrm{~d}$ ). There are particles observed in the polymer matrix in Figure $4 \mathrm{~d}$ which have diameters of $20-40 \mathrm{~nm}$. The complex of PEl and $\mathrm{Cu}^{2+}$ was also subjected to the photo initiated flocculation process with 
2. The large flocculation precipitate showed bulky aggregates which were attributed to the coordination network as well as the cross-linked imine network (Figure 4e). As straight edges were observed in the flocculation precipitate, there could also be a crystallization process during the flocculation.

In summary, we have demonstrated the efficient synthesis and photo-cleavage of thiobenzaldehyde precursors. The photogenerated thiobenzaldehydes are extremely reactive towards amines. Trapping the thiobenzaldehyde from $\mathbf{2}$ with PEI provides a spatially controllable method for PEI crosslinking. This was applied for $\mathrm{Cu}^{2+}$ removal. To the best of our knowledge, it is the first example of using photo-initiated cross-linking for the triggered flocculation application. The photo initiated flocculation system could be further exploited in a radioactive or nuclear polluted environment where spatial control would be beneficial.

\section{EXPERIMENTAL}

General: All commercially obtained solvents and reagents were used without further purification. ${ }^{1} \mathrm{H} \quad$ NMR spectroscopy was conducted on a Varian Unity $300 \mathrm{MHz}$ spectrometer. Chemical shifts $(\delta)$ were reported relative to the solvent residue peak and are in $\mathrm{ppm}\left(\delta_{\mathrm{CHCl} 3}=7.26 \mathrm{ppm}\right)$. Fourier transform infrared spectroscopy was performed on a Perkin Elmer Frontier FT-IR Spectrometer with a universal ATR sampling accessory. UV-Vis spectra were recorded on a Shimadzu UV-Vis Spectrophotometer.

PEI $(M n=0.6 \mathrm{kDa})$ was purchased from SigmaAldrich. UV irradiation was conducted with Philips long wave (355 nm) UV lamp. The UV intensity (at a distance of $0.5 \mathrm{~cm}$ ) is 2.3 $\mathrm{mW} / \mathrm{cm}^{2}$ in the spectral range of $320 \mathrm{~nm}$ to 400 $\mathrm{nm}$ as measured by Solarmeter Model 4.0 UVA Digital UV meter with GaAsP Photodiode.

\section{ACKNOWLEDGEMENTS}

This work was supported by the Victorian Endowment for Science Knowledge and Innovation (LAC).

\section{REFERENCES AND NOTES}

1. F. Ercole, T. P. Davis and R. A. Evans, Polym. Chem. 2010, 1, 37-54.

2. P. Klan, T. Solomek, C. G. Bochet, A. Blanc, R. Givens, M. Rubina, V. Popik, A. Kostikov and J. Wirz, Chem. Rev. 2013, 113, 119-191.

3. Y. Huang, R. J. Dong, X. Y. Zhu and D. Y. Yan, Soft Matter 2014, 10, 6121-6138.

4. Z. Xiao, C. W. Bennett, L. A. Connal, J. Polym. Sci. Part A: Polym. Chem. 2015, 53, 1957-1960.

5. P. Wang, W. Lu, D. A. Devalankar and Z. Ding, Org. Lett. 2015, 17, 2114-2117.

6. A. F. Hirschbiel, B. V. K. J. Schmidt, P. Krolla-Sidenstein, J. P. Blinco and C. Barner-Kowollik, Macromolecules 2015, 48, 4410-4420.

7. O. Altintas, M. Glassner, C. RodriguezEmmenegger, A. Welle, V. Trouillet and C. Barner-Kowollik, Angew. Chem. Int. Ed. 2015, 54, 5777-5783.

8. G. Petzold and S. Schwarz, Adv. Polym. Sci. 2013, 256, 25-65.

9. W. S. Ng, R. Sonsie, E. Forbes and G. V. Franks, Miner. Eng. 2015, 77, 64-71.

10. L. Avadiar, Y.-K. Leong and A. Fourie, Powder Tech. 2014, 254, 364-372.

11. T. M. Madkour, Polymer Data Handbook, Oxford University Press, 1999.

12. Gordon P. Treweek, Dissertation (Ph.D.) California Institute of Technology, 1975.

13. P. Milburn, J. Bonnerjea, M. Hoare and P. Dunnili, Enzyme Microb. Technol. 1990, 12, 527-532.

14. X. Min, C. Qing and C. Jinjin, Water Environ. Res. 2010, 82, 790-796.

15. M. E. Krapf, B. S. Lartiges, C. Merlin, G. Francius, J. Ghanbaja and J. F. Duval, Water Res. 2012, 46, 1838-1846. 
16. T. H. E. E. Vedejs, D. J. Mazur, C. K. McClure, D. A. Perry, R. Ruggeri, E. Schwartz, J. S. Stults, D. L. Varie, R. G. Wilde, and S. Wittenberger, J. Org. Chem. 1986, 51, 1556-1562.

17. J.-H. Wang, Z. Zhang and Y.-L. Feng, Synth. Commun. 1993, 23, 373-377.

18. M. Kaupp, A. S. Quick, C. RodriguezEmmenegger, A. Welle, V. Trouillet, $\mathrm{O}$. Pop-Georgievski, M. Wegener and C. Barner-Kowollik, Adv. Funct. Mater. 2014, 24, 5649-5661.

19. J. Collins, Z. Xiao, A. Espinosa-Gomez, B. P. Fors, L. A. Connal, Polym. Chem. 2016, 7, 2581-2588.
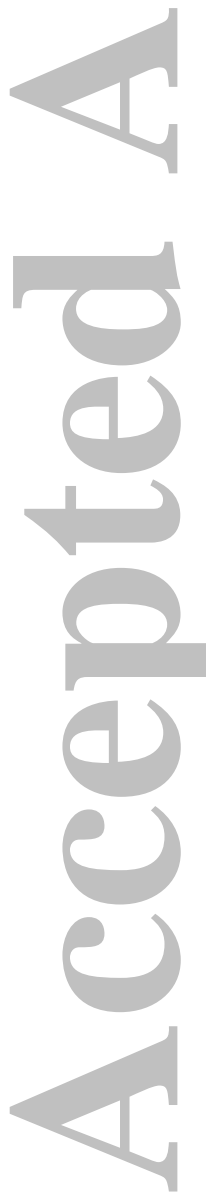

20. J. Collins, Z. Xiao, M. Mullner, L. A. Connal, Polym. Chem. 2016, 7, 38123826.

21. E. R. L. Brisson, Z. Xiao, L. Levin, G. V. Franks, L. A. Connal, Polym. Chem. 2016, 7, 1945-1952.

22. L. Marin, B. Simionescu, and M. Barboiu, Chem. Commun. 2012, 48, 8778-8780.

23. M. Krishnan, J. W. Nalaskowski and L. M. Cook, Chem. Rev. 2010, 110, 178-204.

24. W. K. Maketon, K. L. Ogden, IEEE Trans. Semicond. Manuf. 2008, 21, 481-485.

25. V. N. Kislenko, L. P. Oliynyk, J. Polym. Sci. Part A: Polym. Chem. 2002, 40, 914-922. 
GRAPHICAL ABSTRACT

\section{AUTHOR NAMES}

Zeyun Xiao, ${ }^{1}$ Chao Chen, ${ }^{1}$ Emma Ruth Lucille Brisson, ${ }^{1}$ Joseph Collins, ${ }^{1}$ Wei Sung Ng, ${ }^{1}$ Luke A. Connal ${ }^{1}$

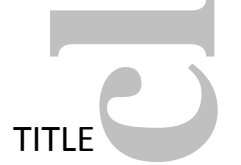

Spatial Control of Flocculation via Light

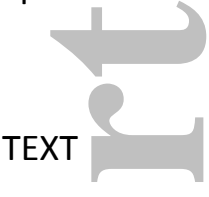

A highly efficient photo-initiated flocculation system formed through the trapping of a photo-generated thiobenzaldehyde with polyethylenimine was developed. This photo responsive system provides spatial and temporal control over flocculation processes and has been applied to heavy metal flocculation.

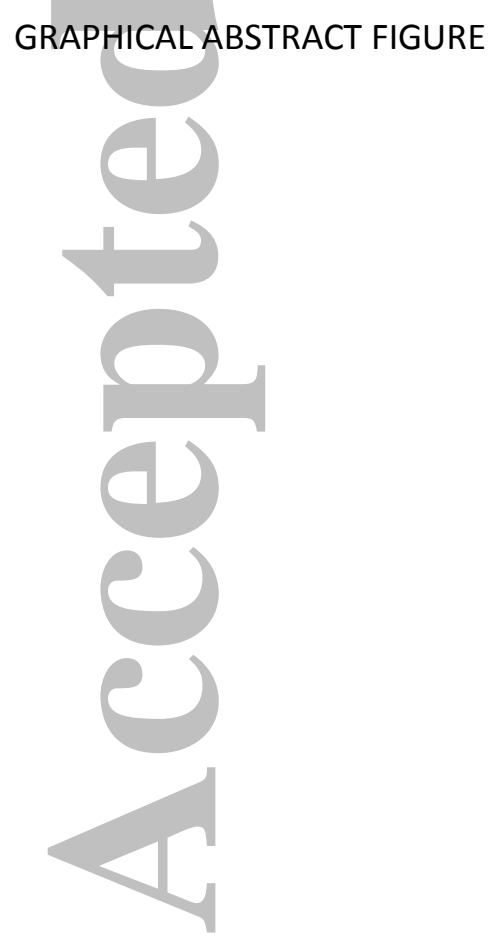




\section{University Library}

\section{- M M N E R VA A gateway to Melbourne's research publications}

Minerva Access is the Institutional Repository of The University of Melbourne

Author/s:

Xiao, Z;Chen, C;Brisson, ERL;Collins, J;Ng, WS;Connal, LA

Title:

Spatial Control of Flocculation Via Light

Date:

2016-11-01

Citation:

Xiao, Z., Chen, C., Brisson, E. R. L., Collins, J., Ng, W. S. \& Connal, L. A. (2016). Spatial Control of Flocculation Via Light. JOURNAL OF POLYMER SCIENCE PART A-POLYMER CHEMISTRY, 54 (21), pp.3407-3410. https://doi.org/10.1002/pola.28242.

Persistent Link:

http://hdl.handle.net/11343/291602 